\title{
Mutation of the sequestosome 1 (p62) gene increases osteoclastogenesis but does not induce Paget disease
}

\author{
Noriyoshi Kurihara, ${ }^{1,2}$ Yuko Hiruma, ${ }^{1,2}$ Hua Zhou, ${ }^{3}$ Mark A. Subler, ${ }^{4}$ \\ David W. Dempster, ${ }^{5}$ Frederick R. Singer, ${ }^{6}$ Sakamuri V. Reddy, ${ }^{7}$ \\ Helen E. Gruber, ${ }^{8}$ Jolene J. Windle, ${ }^{4}$ and G. David Roodman ${ }^{1,2}$
}

\begin{abstract}
1VA Pittsburgh Healthcare System, Research and Development, Pittsburgh, Pennsylvania, USA. 2Division of Hematology/Oncology, Department of Medicine, University of Pittsburgh, Pittsburgh, Pennsylvania, USA. ${ }^{3}$ Regional Bone Center, Helen Hayes Hospital, West Haverstraw, New York, USA. ${ }^{4}$ Department of Human Genetics, Virginia Commonwealth University, Richmond, Virginia, USA. ${ }^{5}$ Department of Pathology, Columbia University College of Physicians and Surgeons, New York, New York, USA. ${ }^{6}$ Endocrine/Bone Disease Program, John Wayne Cancer Institute, Santa Monica, California, USA. ${ }^{7}$ Department of Pediatrics, Children's Research Institute, Medical University of South Carolina, Charleston, South Carolina, USA. ${ }^{8}$ Department of Orthopaedic Surgery, Carolinas Medical Center, Charlotte, North Carolina, USA.
\end{abstract}

\begin{abstract}
Paget disease is the most exaggerated example of abnormal bone remodeling, with the primary cellular abnormality in the osteoclast. Mutations in the $p 62$ (sequestosome 1) gene occur in one-third of patients with familial Paget disease and in a minority of patients with sporadic Paget disease, with the P392L amino acid substitution being the most commonly observed mutation. However, it is unknown how $p 62^{P 392 L}$ mutation contributes to the development of this disease. To determine the effects of $p 62^{P 392 L}$ expression on osteoclasts in vitro and in vivo, we introduced either the $p 62^{P 392 L}$ or WT $p 62$ gene into normal osteoclast precursors and targeted $p 62^{P 392 L}$ expression to the osteoclast lineage in transgenic mice. $p 62^{P 392 L}$-transduced osteoclast precursors were hyperresponsive to receptor activator of NF- $\kappa B$ ligand (RANKL) and TNF- $\alpha$ and showed increased NF- $\kappa B$ signaling but did not demonstrate increased $1,25-(\mathrm{OH})_{2} \mathrm{D}_{3}$ responsivity, $T A F_{I I}-17$ expression, or nuclear number per osteoclast. Mice expressing $p 62^{P 392 L}$ developed increased osteoclast numbers and progressive bone loss, but osteoblast numbers were not coordinately increased, as is seen in Paget disease. These results indicate that $p 62^{P 392 L}$ expression on osteoclasts is not sufficient to induce the full pagetic phenotype but suggest that $p 62$ mutations cause a predisposition to the development of Paget disease by increasing the sensitivity of osteoclast precursors to osteoclastogenic cytokines.
\end{abstract}

\section{Introduction}

Paget disease (PD) is the second most common bone disease in persons of Anglo-Saxon descent over the age of 55 (1). It is the most exaggerated example of disordered bone remodeling, with abnormalities in all phases of the bone remodeling process (2). The primary cellular abnormality resides in the osteoclast (OCL). OCLs in PD are increased in number and size and have increased numbers of nuclei (3). In addition, they are hyperresponsive to $1,25-(\mathrm{OH})_{2} \mathrm{D}_{3}$ and receptor activator of NF- $\mathrm{KB}$ ligand (RANKL) $(4,5)$ and show increased expression of $T A F_{I I}-17$, a member of the $\mathrm{TF}_{\mathrm{II}} \mathrm{D}$ transcription complex, which acts as a coactivator of vitamin $\mathrm{D}$ receptor-mediated transcription and is upregulated in pagetic osteoclasts (6).

Both genetic and environmental factors have been proposed as contributing to the etiology of PD, and multiple families with an autosomal dominant mode of inheritance have been described $(7,8)$. Recently, mutations in the $p 62$ (sequestosome 1) gene have been linked to approximately $30 \%$ of patients with familial PD and to a minority of patients with sporadic PD (8). All of the muta-

Nonstandard abbreviations used: ERK1/2, extracellular signal-regulated kinase $1 / 2$; EV, empty vector; I $\mathrm{B}$, inhibitor of NF- $\kappa \mathrm{B} ; \mathrm{MVNP}$, measles virus nucleocapsid protein; OCL, osteoclast; PD, Paget disease; RANKL, receptor activator of NF- $\mathrm{KB}$ ligand; TRAP, tartrate-resistant acid phosphatase.

Conflict of interest: The authors have declared that no conflict of interest exists. Citation for this article: J. Clin. Invest. 117:133-142 (2007). doi:10.1172/JCI28267. tions identified to date lie within or near the ubiquitin-binding domain in the carboxyterminal region of the protein, with the P392L amino acid substitution representing the most frequently observed mutation (8). $p 62$ plays a critical role in NF-KB activation induced by TNF- $\alpha$, CD 40 , and IL- 1 through its interactions with the atypical protein kinases $\xi \mathrm{PKC}$ and $\lambda \operatorname{PKC}(9,10)$. However, the role of $p 62$ mutations in $\mathrm{PD}$ is unclear since not all individuals carrying a $p 62$ mutation have $\mathrm{PD}(11-13)$.

It is our hypothesis that both genetic and nongenetic factors are required for the development of $\mathrm{PD}$ and that the genetic factors, such as $p 62$ mutations, function to increase OCL formation but are not sufficient to induce the abnormal OCLs or pagetic bone lesions characteristic of PD. To test this hypothesis, we characterized OCL precursors from Paget patients carrying the $p 62^{P 392 L}$ mutation as well as control human OCL precursors transduced with either $p 62$ or $p 62^{P 392 L}$ expression vectors. We also determined whether the $p 62^{P 392 L}$ gene can induce pagetic-like OCLs or bone lesions in vivo when expressed in OCL precursors of transgenic mice.

\section{Results}

OCL precursors from $P D$ patients carrying the $p 62^{P 392 L}$ gene are byperresponsive to $\mathrm{RANKL}, \mathrm{TNF}-\mathrm{\alpha}$, and 1,25- $(\mathrm{OH})_{2} \mathrm{D}_{3}$ and express increased levels of $T A F_{I I}-17$. OCL precursors from $\mathrm{PD}$ patients carrying the $p 62^{\text {P392L }}$ mutation or from controls were compared for their capacity to form OCLs over a range of concentrations of RANKL, TNF- $\alpha$, and $1,25-(\mathrm{OH})_{2} \mathrm{D}_{3}$. OCL precursors from patients carry- 

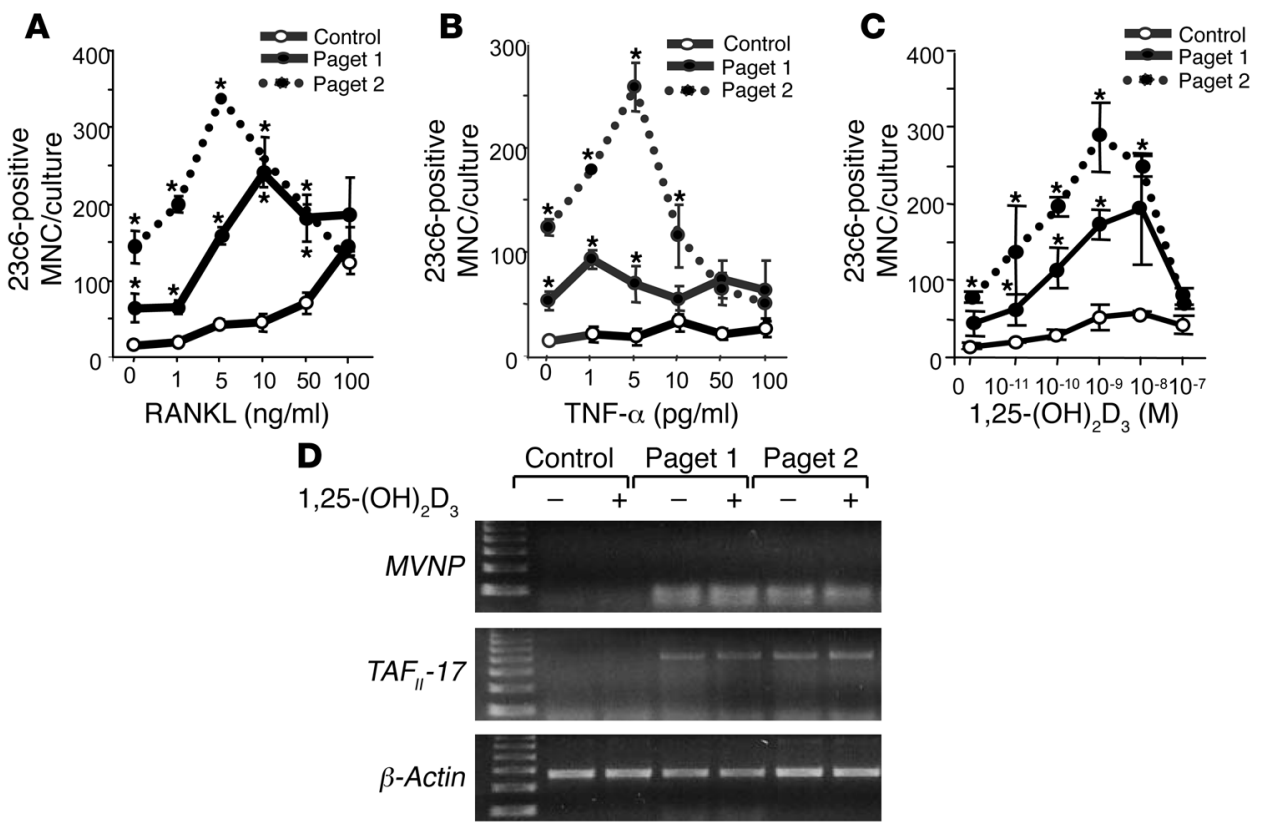

Figure 1

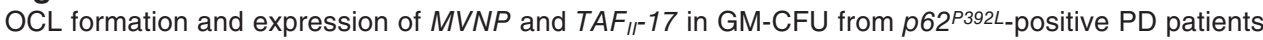
and controls. (A-C) GM-CFU ( $10^{5}$ cells/well) from Paget patients known to harbor the $p 62^{P 392 L}$ mutation and from normal individuals were cultured for OCL formation in the presence of RANKL (A), TNF- $\alpha$ (B), or $1,25-(\mathrm{OH})_{2} \mathrm{D}_{3}(\mathbf{C})$. After 3 weeks of culture, cells were fixed and stained with the $23 \mathrm{c} 6$ monoclonal antibody, which identifies OCLs. Results are expressed as the mean \pm SEM for quadruplicate determinations. *Significant differences $(P<0.001)$ compared with results from cultures of normal GM-CFU treated with the same concentration of each factor. A similar pattern of results was seen in 2 independent experiments. Paget 1 and Paget 2 refer to PD patient sample groups 1 and 2. MNC, multinuclear cell.

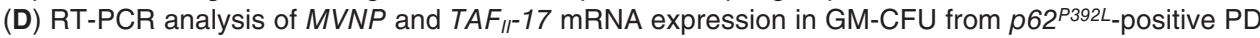
patients and controls cultured for 2 days with $1,25-(\mathrm{OH})_{2} \mathrm{D}_{3}$. RT-PCR analysis of $\beta$-actin expression was included as a control for mRNA quality and amplification.

ing the $p 62^{P 392 L}$ mutation were hyperresponsive to RANKL and TNF- $\alpha$ as well as $1,25-(\mathrm{OH})_{2} \mathrm{D}_{3}$ (Figure $\left.1, \mathrm{~A}-\mathrm{C}\right)$; this is similar to previous findings from patients with sporadic PD (3-5). In cultures of OCL precursors from PD patients with $p 62^{P 392 L}$ mutations, maximum OCL formation was obtained at RANKL and TNF- $\alpha$ concentrations of $1-10 \mathrm{ng} / \mathrm{ml}$ and $1-10 \mathrm{pg} / \mathrm{ml}$, respectively, compared with $100 \mathrm{ng} / \mathrm{ml}$ and $50 \mathrm{pg} / \mathrm{ml}$ for normal OCL precursors. Similar results were obtained with 3 individual PD patients. Further, the OCLs that formed contained increased numbers of nuclei per OCL (Table 1) and elevated expression of $T_{A F_{I}-17}$ (Figure 1D). However, measles virus nucleocapsid protein $(M V N P)$ transcripts were also present in OCLs from these patients (Figure 1D), raising the possibility that a subset of the phenotypic characteristics of these OCLs might be caused by the presence of $M V N P$ rather than $p 62^{P 392 L}$.

OCL formation by $p 62$ - and $p 62^{P 392 L}$-transduced normal OCL precursors. To further dissect the role of $p 62^{P 392 L}$ in $\mathrm{PD}$, we transduced normal human OCL precursors with the WT $p 62$ or $p 62^{P 392 L}$ gene or empty vector $(E V)$. The total p62 expression levels were determined by immunoblotting extracts from transduced GM-CFU-derived cells with an antibody that recognizes both WT and mutant $p 62$. The $p 62$ protein was detected in both $p 62$ - and $p 62^{P 392 L}$-transduced GM-CFU without treatment with RANKL. In contrast, $p 62$ protein was only detected in $E V$-transduced GM-CFU after 1 day of treatment with RANKL (data not shown). p62 $2^{P 392 L}$-transduced OCL precursors treated with varying concentrations of RANKL or TNF- $\alpha$ were found to be hyperresponsive to both cytokines and formed increased numbers of OCLs (Figure 2, A and B). While overexpression of WT $p 62$ resulted in a degree of hyperresponsivity to RANKL similar to that of $p 62^{P 392 L}$, the $p 62^{P 392 L}$ cells were much more hyperresponsive to TNF- $\alpha$ than WT p62 cells. Both p62- and

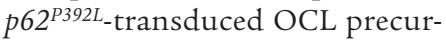
sors formed significantly larger OCLs than EV cells (Figure 2D), although nuclear number per OCL was not increased in $p 62$ - or

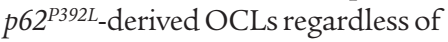
treatment (Table 1). Also, a 7-fold increase in bone resorption was observed when OCLs formed by $p 62^{P 392 L}$-transduced human GM-CFU were treated with RANKL (50 ng/ml) and cultured on dentin, as compared with RANKL-treated $E V$-transduced OCLs (Figure 3, A and B).

In contrast with the results with RANKL and TNF- $\alpha$, neither p62-nor $p 62^{P 392 L}$-transduced OCL precursors were hyperresponsive to $1,25-(\mathrm{OH})_{2} \mathrm{D}_{3}$ (Figure $2 \mathrm{C}$ ) or formed increased numbers of OCLs compared with EV-transduced cells. In addition, neither $p 62$ - nor $p 62^{P 392 L}$-transduced GM-CFU-derived cells showed elevated expression of $T A F_{I I}-17$ in the presence or absence of $10^{-10} \mathrm{M} 1,25-(\mathrm{OH})_{2} \mathrm{D}_{3}$ (Figure 4).

Effects of $p 62^{P 392 L}$ expression on OCLs in vivo. Since OCLs harbor the primary cellular abnormality in PD, we used the tartrate-resistant acid phosphatase (TRAP) promoter to target expression of the human $p 62^{P 392 L}$ gene to the OCL lineage in transgenic mice (TRAP- $p 62^{P 392 L}$ mice) to determine the effects of $p 62^{P 392 L}$ expression in OCLs in vivo. Eight lines of TRAP-p62 ${ }^{P 392 L}$ transgenic mice were generated from independent founder mice, and each of these was characterized with regard to transgene expression level, TNF- $\alpha$ responsivity, and histology. The results described below were obtained from a single line (Tp62 2 2), although similar results were observed in multiple other lines as well. The expression levels of total p62 protein in mice of the Tp $62 \mathrm{~m} 2$ line, as determined by immunoblotting of extracts from bone marrow cells with an antibody that detects both murine and human $p 62$, were found to be approximately 2.5 -fold higher than $p 62$ levels in WT mice (data not shown).

Histomorphometric evaluation of vertebral bones from TRAP- $p 62^{P 392 L}$ mice at $4,8,12$, and 16 months of age revealed an increase in OCL perimeter (the amount of bone surface covered with TRAP-positive, mono-, and multinuclear cells) and a progressive reduction in cancellous bone volume when compared with that of age-matched WT controls (Table 2 and Supplemental Figure 1; supplemental material available online with this article; 
Table 1

Nuclear number per OCL

\begin{tabular}{|c|c|c|c|c|}
\hline Cell type & Vehicle & $\begin{array}{c}1,25-(\mathrm{OH})_{2} \mathrm{D}_{3} \\
\left(10^{-8} \mathrm{M}\right)\end{array}$ & $\begin{array}{c}\text { RANKL } \\
(50 \mathrm{ng} / \mathrm{ml})\end{array}$ & $\begin{array}{c}\text { TNF- } \alpha \\
(50 \mathrm{pg} / \mathrm{ml})\end{array}$ \\
\hline Control human & $10 \pm 3$ & $13 \pm 2$ & $12 \pm 2$ & $13 \pm 2$ \\
\hline Familial PD & $24 \pm 3$ & $52 \pm 13^{A}$ & $32 \pm 5^{A}$ & $25 \pm 4^{\mathrm{A}}$ \\
\hline Human GM-CFU-EV & $6 \pm 3$ & $7 \pm 2$ & $12 \pm 5$ & $7 \pm 2$ \\
\hline Human GM-CFU-p62P392L & $5 \pm 3$ & $7 \pm 2$ & $10 \pm 2$ & $8 \pm 2$ \\
\hline WT mice & $5 \pm 3$ & $6 \pm 2$ & $9 \pm 2$ & $5 \pm 2$ \\
\hline TRAP-p62P392L mice & $5 \pm 3$ & $6 \pm 2$ & $9 \pm 2$ & $5 \pm 2$ \\
\hline
\end{tabular}

The number of nuclei per OCL was determined in 20 random 23c6-positive or TRAP-positive OCLs for each treatment group. Results are expressed as mean \pm S.D. ASignificantly different from the same treatment as the normal donor, $P<0.01$.

doi:10.1172/JCI28267DS1). The decrease in cancellous bone volume was associated with decreases in both trabecular width and number. Although OCL perimeter was elevated, there was no coupled increase in osteoblast perimeter, as is seen in PD lesions.

Electron microscopic examination of OCLs from TRAP-p62 $2^{P 392 L}$ mice demonstrated that the cells did not contain the nuclear inclusions characteristic of pagetic OCLs. OCLs were similar to those in WT controls in terms of nuclear and cytoplasmic ultrastructure as well in the morphology of the ruffled border (data not shown).

OCL precursors from TRAP-p $62^{P 392 L}$ mice are byperresponsive to RANKL and TNF- $\alpha$ but not 1,25- $(\mathrm{OH})_{2} \mathrm{D}_{3}$. When marrow cells from
TRAP- $p 62^{P 392 L}$ mice were cultured with RANKL and TNF- $\alpha$ to induce OCL formation, they were found to be hyperresponsive to both cytokines, and they formed increased numbers of OCLs as compared with nontransgenic littermates (Figure 5, A and B). Similarly, treatment of TRAP- $p 62^{P 392 L}$ mice with TNF- $\alpha(0-1.5 \mu \mathrm{g} / \mathrm{d})$ significantly increased OCL formation compared with that of WT mice at all concentrations tested (Figure 5, E and G). Further, the dose-response curves for NF- $\mathrm{KB}$ reporter gene activity in TRAP- $p 62^{P 392 L}$ OCL precursors for both RANKL and TNF- $\alpha$ were shifted to the left compared with cells from WT mice (Figure 5, D and E). However, OCL precursors from TRAP-p62 $2392 L$ mice were not hyperresponsive to $1,25-(\mathrm{OH})_{2} \mathrm{D}_{3}$ (Figure $5 \mathrm{C}$ ) and did not express detectable $T A F_{I I}-17$ (data not shown). They also did not have increased nuclear number per OCL (Table 1). These results are consistent with our results from $p 62^{P 392 L}$-transduced human OCL precursors and indicate that expression of $p 62^{P 392 L}$ induces a subset of pagetic characteristics, including hyperresponsivity to the osteoclastogenic cytokines RANKL and TNF- $\alpha$, but does not result in development of OCLs that express the complete pagetic phenotype or development of pagetic-like lesions.

To further examine the mechanisms responsible for the increased levels of OCL formation in marrow cultures from TRAP- $p 62^{P 392 L}$ mice, we determined the time course for OCL formation, the rates of proliferation of OCL precursors and of OCL apoptosis, and the expression levels of OCL differentiation markers. As shown in Figure 6A, OCL formation in marrow cultures from TRAP- $p 62^{P 392 L}$
A

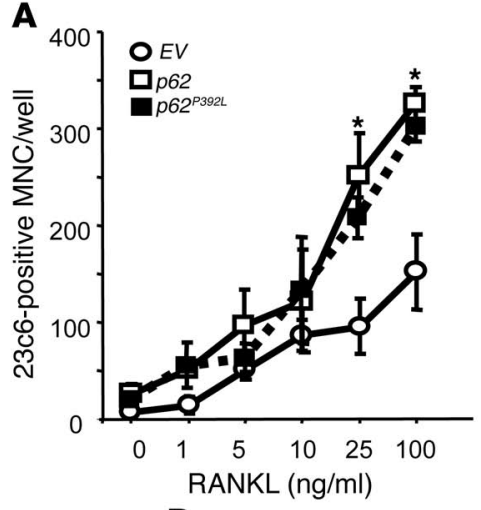

D

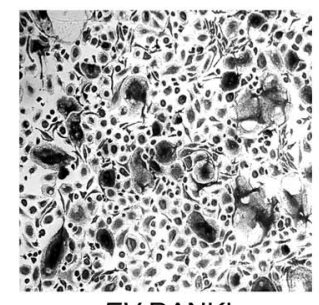

EV RANKL

$(100 \mathrm{ng} / \mathrm{ml})$
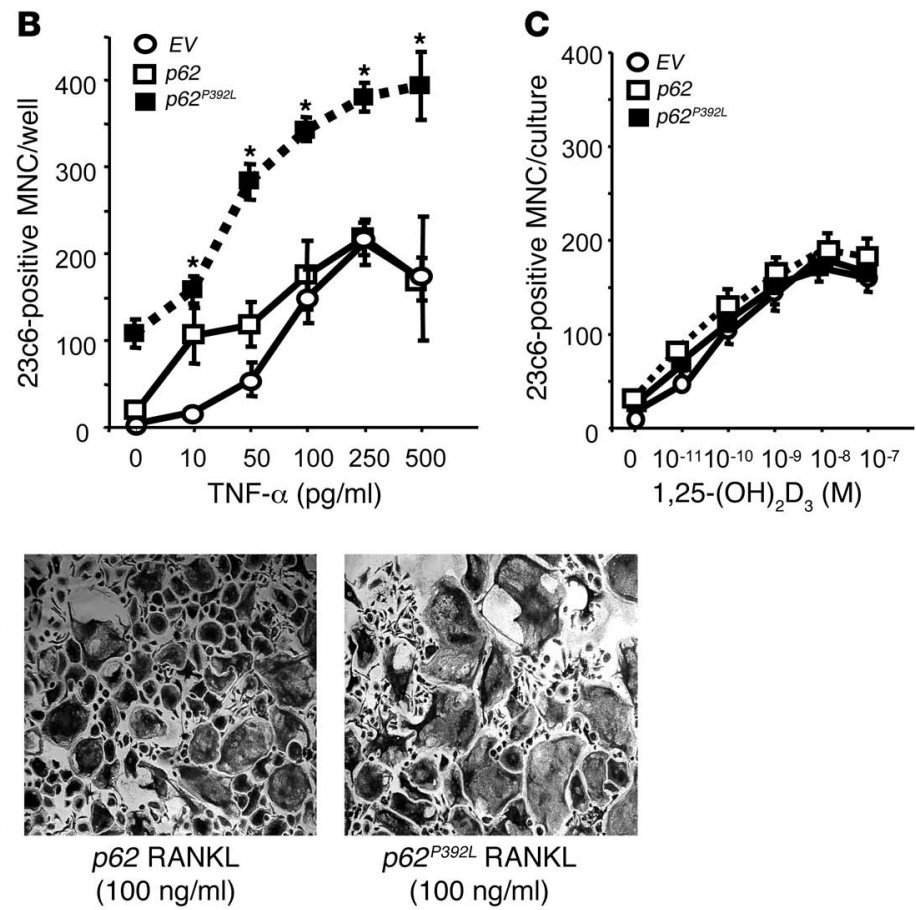

Figure 2

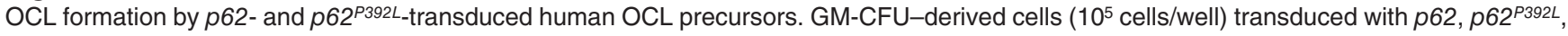
or EV were cultured with RANKL (A), TNF- $\alpha(\mathbf{B})$, or $1,25-(\mathrm{OH})_{2} \mathrm{D}_{3}(\mathbf{C})$. After 3 weeks of culture, cells were fixed and stained with the $23 \mathrm{c} 6$ monoclonal antibody, which identifies OCLs. Results are expressed as the mean \pm SEM for quadruplicate cultures from a typical experiment. *Significant differences $(P<0.001)$ compared with results of $E V$-transduced cell cultures treated with the same concentration of individual factors.

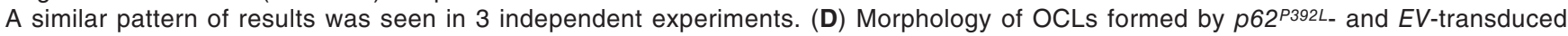
GM-CFU-derived cells. Original magnification, $\times 100$. 
A

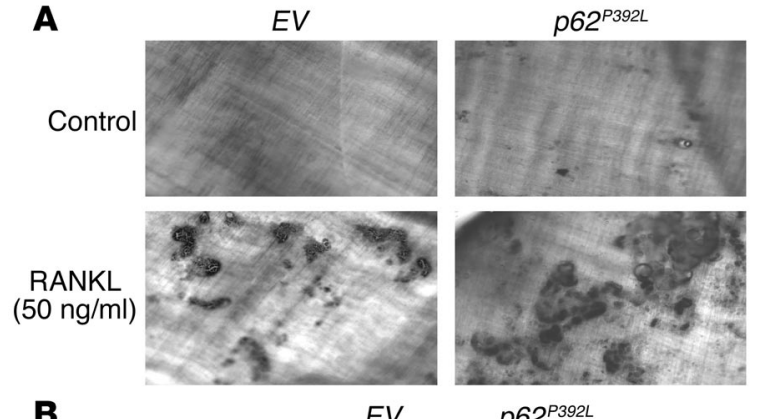

B

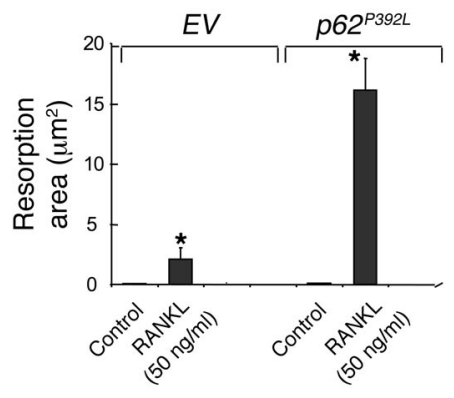

Figure 3

Resorption lacunae formed by OCLs from $p 62^{P 392 L}$ - and $E V$-transduced human GM-CFU. (A) Resorption lacunae formed on dentin by OCL. Original magnification, $\times 100$. (B) Resorption areas per dentin slice for each treatment group. Results represent mean \pm SEM for quadruplicate determinations for a typical experiment. Similar results were seen in 3 independent experiments. ${ }^{*}$ Significant differences $(P<0.05)$.

mice was maximum after 6 days of culture while OCL formation in WT cultures was maximum at 9 days of culture. Further, OCL precursor proliferation was significantly increased in marrow cultures from $p 62^{\text {P392L }}$ mice compared with WT cultures but followed a similar time course (Figure 6B). In contrast, although the number of apoptotic OCLs was increased in TRAP- $p 62^{P 392 L}$ marrow cultures compared with WT marrow cultures, the percentages of apoptotic OCLs were similar (18\% versus $10 \% ; P>0.05)$ in TRAP- $p 62^{P 392 L}$ and WT cultures after 9 days (Figure 6C). Apoptotic OCLs were not detected in cultures of mice from either genotype at day 3 or 6 of culture. Marrow cultures from TRAP- $p 62^{P 392 L}$ mice expressed relatively higher levels of TRAP, cathepsin $\mathrm{K}$, and calcitonin receptor mRNA compared with WT cultures (Figure 7).

Since OCL precursors from Paget patients carrying the P392L mutation were hyperresponsive to $1,25-(\mathrm{OH})_{2} \mathrm{D}_{3}$ and also expressed $M V N P$, we transfected OCL precursors from TRAP- $p 62^{P 392 L}$ mice with MVNP and determined their responsivity to $1,25-(\mathrm{OH})_{2} \mathrm{D}_{3}$. As shown in Figure 8, OCL precursors from TRAP- $p 62^{P 392 L}$ mice transfected with $M V N P$ were hyperresponsive to $1,25-(\mathrm{OH})_{2} \mathrm{D}_{3}$ and formed OCL at concentrations that were 1 to 2 logs lower than those of $E V$-transfected cells.

To further delineate the mechanisms responsible for the enhanced OCL formation in TRAP- $p 62^{P 392 L}$ mice, we examined

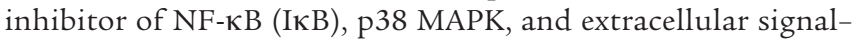
regulated kinase $1 / 2(E R K 1 / 2)$ signaling in nonadherent marrow cells from WT and TRAP- $p 62^{P 392 L}$ mice. As shown in Supplemental Figure 2A, p-ERK1/2 was increased in marrow cells treated with RANKL or TNF- $\alpha$ while only modest changes were seen in p38 MAPK and p-IкB activity. Transfection of GM-CFU from WT and TRAP- $p 62^{P 392 L}$ mice with the MVNP gene further increased levels of NF- $\kappa \mathrm{B}$ in TRAP- $p 62^{P 392 L}$ OCL precursors compared with those of WT precursors (Supplemental Figure 2B). Expression of MVNP in OCL precursors from WT or TRAP- $p 62^{P 392 L}$ mice did not increase expression of c-Fos.

\section{Discussion}

Mutations in the p62 gene have been linked to PD in approximately one-third of patients with familial PD and a minority of patients with sporadic PD. However, it is unlikely that these mutations are sufficient to induce the OCL abnormalities and bone lesions that are characteristic of $\mathrm{PD}$, since pagetic lesions are focal even in patients carrying germline $p 62$ mutations and some individuals harboring $p 62$ mutations fail to develop PD (11-13). To determine the role of $p 62$ mutation in $\mathrm{PD}$, we characterized OCL precursors from familial PD patients carrying the most common PD-associated $p 62$ mutation (P392L) and compared them with normal OCL precursors. OCL precursors from $p 62^{P 392 L}$-positive $\mathrm{PD}$ patients formed OCLs at lower concentrations of RANKL, TNF- $\alpha$, and $1,25-(\mathrm{OH})_{2} \mathrm{D}_{3}$ than controls (Figure $\left.1, \mathrm{~A}-\mathrm{C}\right)$ and had increased $\mathrm{TAF}_{\mathrm{II}}-17$ expression (Figure 1D), all characteristic of $\mathrm{PD}$; this was similar to our previous findings in OCL precursors from patients with sporadic PD (3-6). However, OCL precursors from these patients also expressed MVNP, which we have previously reported results in increased OCL formation in response to RANKL and 1,25- $(\mathrm{OH})_{2} \mathrm{D}_{3}$ and to increased expression of $T A F_{I I}-17$ both in vitro and in vivo $(6,14)$.

To further characterize the contributions of $p 62^{P 392 L}$ to $\mathrm{PD}$ in the absence of $M V N P$, we transduced normal human OCL precursors with vectors encoding WT $p 62$ or $p 62^{P 392 L}$ or with $E V$. As with OCL precursors from $P D$ patients, $p 62^{P 392 L}$-transduced OCL precursors showed increased TNF- $\alpha$ and RANKL sensitivity (Figure 2, A and B) but, in contrast, did not demonstrate increased $1,25-(\mathrm{OH})_{2} \mathrm{D}_{3}$ responsivity (Figure 2C) or increased expression of $T A F_{I T}-17$ (Figure 4). In addition, nuclear number per OCL was not increased in $p 62^{P 392 L_{-}}$ transduced OCLs (Table 1). Thus, these OCLs express only a subset of the characteristics of pagetic OCLs (15). Similar results were obtained when expression of the $p 62^{P 392 L}$ gene was targeted to cells in the OCL lineage in vivo. OCL precursors from TRAP- $p 62^{P 392 L}$ mice were hyperresponsive to RANKL and TNF- $\alpha$ but not to $1,25-(\mathrm{OH})_{2} \mathrm{D}_{3}$ (Figure 5, $\mathrm{A}-\mathrm{C})$ and did not express increased levels of $T A F_{I I}-17$. Further, OCL formation in TRAP- $p 62^{P 392 L}$ mice was significantly increased in vivo by treatment with TNF- $\alpha$ (Figure $5, \mathrm{~F}$ and $\mathrm{G}$ ).

Both RANKL and TNF- $\alpha$ activate signaling pathways involving p62 that ultimately lead to the activation of NF- $\mathrm{kB}, \mathrm{p} 38 \mathrm{MAPK}$, and ERK1/2, which are important for OCL formation and function.

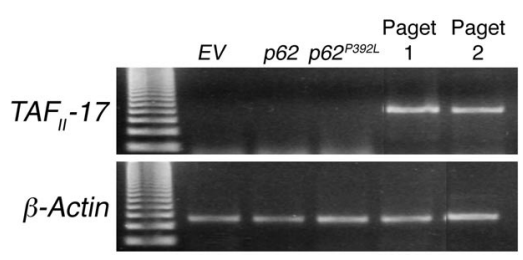

\section{Figure 4}

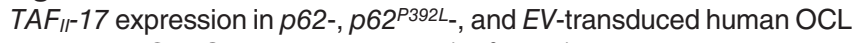
precursors.GM-CFU-derived cells $\left(10^{6}\right.$ cells) transduced with $p 62$, p62 $2^{P 392 L}$, and $E V$ were cultured for 2 days with $10^{-8} \mathrm{M} 1,25-(\mathrm{OH})_{2} \mathrm{D}_{3}$. RNA was then prepared and subjected to RT-PCR analysis of $T A F_{I I}-17$ or $\beta$-actin expression. The 2 PD patient samples shown in Figure 1 were used as positive controls. 
Table 2

Cancellous bone structure and bone turnover in TRAP-p62P392L mice

\begin{tabular}{|c|c|c|c|c|c|c|c|c|}
\hline Variable & $\begin{array}{c}\text { WT } \\
4 \text { mo }\end{array}$ & $\begin{array}{c}\text { p62 } \\
4 \text { mo }\end{array}$ & $\begin{array}{c}\text { WT } \\
8 \mathrm{mo}\end{array}$ & $\begin{array}{c}\text { p62 } \\
8 \mathrm{mo}\end{array}$ & $\begin{array}{c}\text { WT } \\
12 \mathrm{mo}\end{array}$ & $\begin{array}{c}\text { p62 } \\
12 \mathrm{mo}\end{array}$ & $\begin{array}{c}\text { WT } \\
16 \mathrm{mo}\end{array}$ & $\begin{array}{c}\text { p62 } \\
16 \mathrm{mo}\end{array}$ \\
\hline & $n=16$ & $n=9$ & $n=20$ & $n=11$ & $n=15$ & $n=3$ & $n=5$ & $n=11$ \\
\hline$=: M$ & $14: 2$ & $7: 2$ & $15: 5$ & $6: 5$ & $13: 2$ & $3: 0$ & $3: 2$ & $1: 10$ \\
\hline BV/TV (\%) & $19.1 \pm 0.8$ & $15.4 \pm 1.3^{B}$ & $15.3 \pm 1.0$ & $13.6 \pm 0.7^{B}$ & $16.2 \pm 1.1$ & $11.5 \pm 1.7^{\mathrm{B}}$ & $17.6 \pm 2.3$ & $12.7 \pm 1.0^{\mathrm{B}}$ \\
\hline Tb.Wi $(\mu m)$ & $36.6 \pm 1.0$ & $33.6 \pm 0.9^{B}$ & $35.5 \pm 1.3$ & $32.9 \pm 0.7^{B}$ & $39.0 \pm 1.7$ & $35.3 \pm 3.7^{B}$ & $39.9 \pm 3.3$ & $32.2 \pm 1.0^{B}$ \\
\hline Tb.N (per $\left.m m^{2}\right)^{\mathrm{C}}$ & $5.2 \pm 0.2$ & $4.5 \pm 0.2^{\mathrm{A}}$ & $4.3 \pm 0.2$ & $4.1 \pm 0.2^{A}$ & $4.2 \pm 0.3$ & $3.2 \pm 0.2^{A}$ & $4.4 \pm 0.4$ & $3.9 \pm 0.3^{A}$ \\
\hline Tb.Sp $(\mu m)$ & $158.2 \pm 6.6$ & $189.9 \pm 10.1^{\mathrm{A}}$ & $212.0 \pm 14.0$ & $216.0 \pm 12.9^{A}$ & $214.8 \pm 17.5$ & $277.0 \pm 22.6^{A}$ & $198.6 \pm 29.1$ & $235.6 \pm 20.3^{A}$ \\
\hline Oc.Pm (\%) & $19.4 \pm 0.8$ & $22.7 \pm 1.7^{\mathrm{B}}$ & $18.0 \pm 0.9$ & $20.8 \pm 2.0^{B}$ & $17.6 \pm 0.7$ & $27.4 \pm 3.9^{B}$ & $16.8 \pm 1.7$ & $20.6 \pm 2.3^{B}$ \\
\hline Ob.Pm (\%) & $12.3 \pm 1.3$ & $10.8 \pm 1.6$ & $8.4 \pm 0.9^{D}$ & $7.4 \pm 0.8^{D}$ & $8.8 \pm 1.0^{\mathrm{D}}$ & $4.5 \pm 1.9^{D}$ & $8.9 \pm 1.7^{D}$ & $13.0 \pm 0.9^{D}$ \\
\hline
\end{tabular}

Data are expressed as mean \pm SEM. P62, TRAP-p62 P392L mice; BV/TV, cancellous bone volume; Tb.Wi, trabecular width; Tb.N, trabecular number; Tb.Sp, trabecular separation; Oc.Pm, OCL perimeter; and Ob.Pm, osteoblast perimeter. Data were analyzed using 2-way ANOVA. Significant differences are indicated as follows: ${ }^{A} P<0.05$ and ${ }^{B} P<0.01$ versus $\mathrm{WT} ;{ }^{C} P<0.05$ and ${ }^{D} P<0.01$ versus 4 -month group. A significant interaction $(P<0.05)$ between the factors of treatment ( $p 62$ or WT) and age $(4,8,12$, and 16 months) is noted in the variable of osteoblast perimeter.

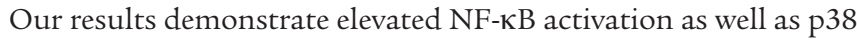
MAPK and ERK1/2 signaling in OCLs expressing p $62^{\text {P392L }}$, strongly suggesting that Paget-associated mutations in p62 lead to increased osteoclastogenesis by stimulating signaling pathways that activate NF-кB (Supplemental Figure 2A). However, the detailed mechanisms by which these $\mathrm{p} 62$ mutations activate signaling remain to be determined. All of the PD-associated $p 62$ mutations reside in or near the ubiquitin-binding domain and result in loss of the ubiquitin-binding capacity of $p 62$ (16). Thus, it is possible that the ubiquitin-binding domain of $p 62$ normally mediates a protein/protein interaction that dampens NF- $\kappa B$ signaling in OCLs in response to inflammatory cytokines, such that loss of this interaction leads to increased activation of these pathways.

It is interesting to note that in both transduced human OCL precursors and in transgenic mouse OCL precursors, expression of $p 62^{P 392 L}$ had a much more dramatic effect on responsivity to TNF- $\alpha$ than to RANKL. Consistent with our results, Duran et al. have reported that the P392L mutation in p62 increased NF- $\kappa B$ reporter activity (17). These results suggest that TNF- $\alpha$, in addition to RANKL and $1,25-(\mathrm{OH})_{2} \mathrm{D}_{3}$, may be involved in the increased osteoclastogenesis in PD and should be studied further.

Histomorphometric analysis of vertebral cancellous bone in the TRAP- $p 62^{P 392 L}$ transgenic mice revealed a phenotype that was characterized by low bone volume with reduced trabecular number and width. OCL perimeter was increased at all ages examined, but there was no coupled increase in osteoblast perimeter. This marked imbalance between OCL formation and new bone formation is analogous to imbalance in inflammatory diseases of bone, such as rheumatoid arthritis and lytic bone metastases, in which bone formation is suppressed, rather than PD, in which OCL activity is closely coupled to new bone formation. This phenotype is very different from that observed in TRAP-MVNP transgenic mice, which persistently express the gene encoding the MVNP (14). In contrast with TRAP- $p 62^{P 392 L}$ mice, TRAP-MVNP mice displayed a bone phenotype that closely resembled PD in humans. This included a coupled increase in both bone resorption and new bone formation and enlarged OCLs with increased nuclear number (14). Moreover, a subset (30\%) of 12-month-old TRAP-MVNP mice displayed pagetic-like lesions, with increased bone volume and dramatically thickened and disorganized trabeculae composed primarily of woven bone. No such lesions were observed in the TRAP-p62 $6392 L$ mice, which were examined up until 18 months of age. In addition, OCL precursors from the TRAP-MVNP mice showed increased sensitivity to $1,25-(\mathrm{OH})_{2} \mathrm{D}_{3}$ and expressed increased levels of $T A F_{I I}-17$, findings that were not observed in the TRAP- $p 62^{P 392 L}$ mice unless the cells were transfected with MVNP (Figure 8). Finally, transfection of OCL precursors from TRAP- $p 62^{P 392 L}$ mice with MVNP further increased levels of NF- $\kappa \mathrm{B}$, suggesting that $M V N P$ can increase the enhanced OCL formation induced by the $p 62^{P 392 L}$ mutation (Supplemental Figure 2B).

One possible explanation for the failure of the TRAP- $p 62^{P 392 L}$ mice to display increased osteoblast activity is that expression of p62 $2^{P 392 L}$ is restricted to cells of the OCL lineage in this model while familial PD patients carrying a p62 mutation express the mutant protein in all cell types. It remains to be determined whether the p62 mutation plays a direct role in other cell types besides OCL in PD. It will therefore be of interest to evaluate the bone phenotype in knockin mice carrying the analogous $p 62$ mutation in the germline, which are currently being developed.

Taken together, these results demonstrate that the expression of p62 $2^{\text {P392L }}$ in OCLs increases OCL formation but is not sufficient to induce PD. Thus, $p 62$ mutations may predispose to the development of PD by increasing basal OCL activity, but 1 or more additional factors are required for development of the full PD phenotype.

\section{Methods}

Chemicals. FBS was purchased from Invitrogen. All other chemicals and media were purchased from Sigma-Aldrich, unless otherwise noted. RANKL, TNF- $\alpha$, IL-3, IL-6, and GM-CSF were purchased from R\&D Systems. The $1,25-(\mathrm{OH})_{2} \mathrm{D}_{3}$ was generously provided by Teijing Corp.

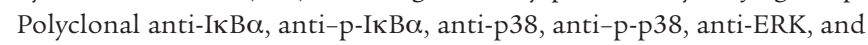
anti-p-ERK antibodies were from Cell Signaling Technology. Protease inhibitor mixtures and SB203580 were from Calbiochem.

Isolation of OCL precursors from PD patients carrying the $p 62^{P 392 L}$ mutation and from normal individuals. After obtaining informed consent, we obtained heparinized peripheral blood from 3 patients with PD and 3 age-matched controls. These studies were approved by the Institutional Review Boards at the University of Pittsburgh and the John Wayne Cancer Institute. Nonadherent peripheral blood mononuclear cells were isolated as previously described (18). The cells were cultured in methylcellulose in the presence of $100 \mathrm{pg} / \mathrm{ml}$ of recombinant human GM-CSF to form GM-CFU colonies. Individual colonies were pooled after 7 days of culture. Aliquots from the 
A

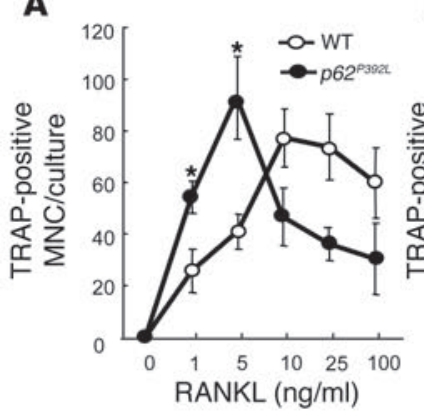

B

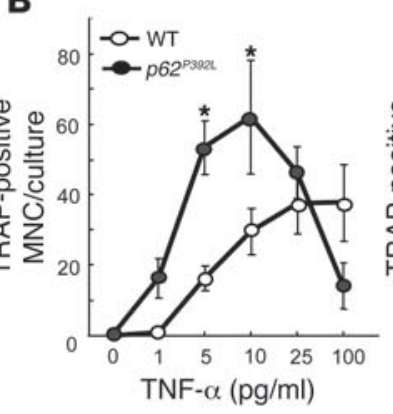

C

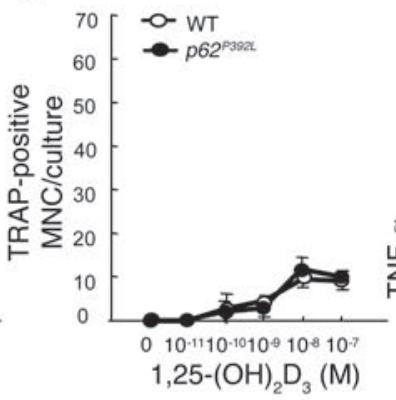

F

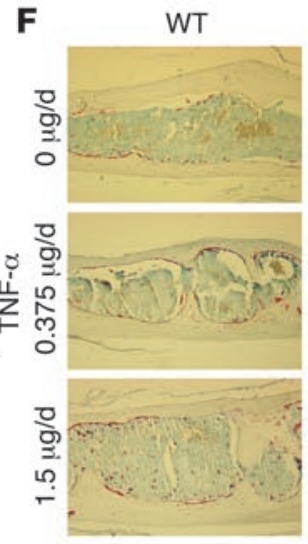

p62 $2^{\text {P392L }}$

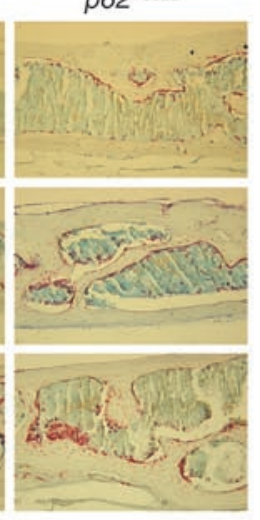

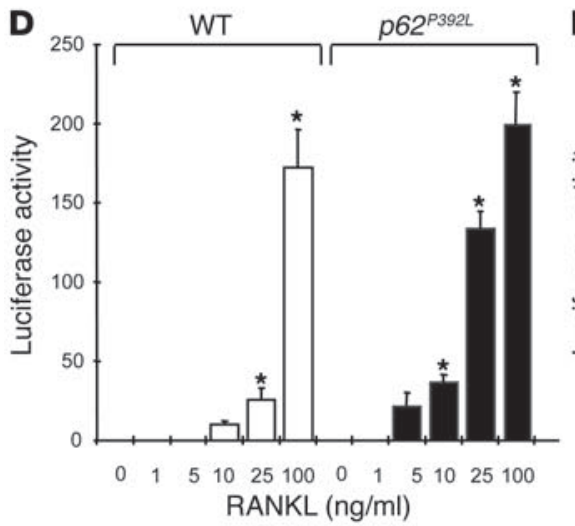

E WT

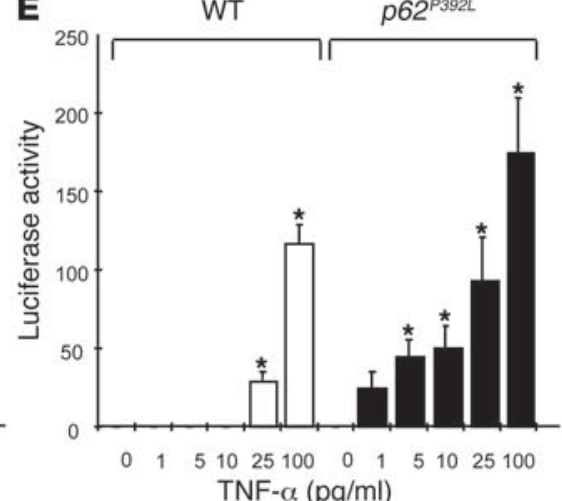

G

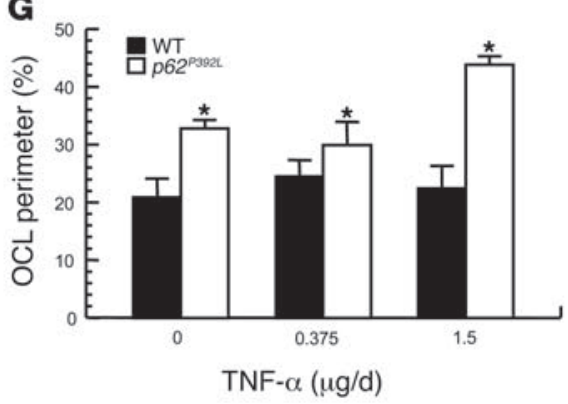

Figure 5

OCL formation and NF-kB gene reporter activity in OCL precursors from TRAP-p62 $2^{P 392 L}$ and WT mice. (A-C) OCL precursors (105 cells/well) from TRAP-p62 ${ }^{P 392 L}$ and WT mice were cultured in the presence of RANKL (A), TNF- $\alpha$ (B), or 1,25- $(\mathrm{OH})_{2} \mathrm{D}_{3}(\mathbf{C})$. After 6 days of culture, cells were fixed and stained for TRAP activity. Results are expressed as mean \pm SEM for quadruplicate cultures from a typical experiment. ${ }^{*} P<0.001$ compared with results in WT cell cultures. Similar results were obtained in 5 independent experiments. Activation of NF-кB was measured by cotransfection of an NF- $\mathrm{KB}$ reporter plasmid and a $\beta$-gal expression vector into TRAP-p62 ${ }^{\mathrm{P} 392 L}$ or WT OCL precursors following 24 hours of treatment with RANKL (D) or TNF- $\alpha(E)$. The results are expressed as the mean \pm SEM for the ratio of NF-kB reporter activity to $\beta$-gal activity for quadruplicate determinations. ${ }^{*}$ Significant differences $(P<0.001)$ compared with results with WT cultures. A similar pattern of results was seen in 2 independent experiments. (F) Six-month-old TRAP-p62 ${ }^{P 392 L}$ and WT mice were injected over the calvaria for 5 days with TNF- $\alpha$ $(0,0.375 \mu \mathrm{g}$, and $1.5 \mu \mathrm{g} /$ day). Calvaria were harvested and tissue sections stained for TRAP activity (red color). Original magnification, $\times 100$. (G) TRAP-positive OCL perimeter on the endosteal surface of calvaria in WT and TRAP-p62 ${ }^{P 392 L}$ mice. * Significant differences $(P<0.01)$ between TRAP-p62 ${ }^{P 392 L}$ and WT mice were found by 2-way ANOVA.

pooled colonies were cultured in the presence of RANKL, TNF- $\alpha$, or 1,25$(\mathrm{OH})_{2} \mathrm{D}_{3}$ to induce OCL formation as described below.

Long-term cultures for OCL formation. For experiments employing highly purified OCL precursors, GM-CFU-derived cells, prepared as described above, were cultured in 96-well plates in $\alpha$-MEM containing $20 \%$ horse serum and varying concentrations of RANKL, TNF- $\alpha$, or $1,25-(\mathrm{OH})_{2} \mathrm{D}_{3}$. Every 3 days, half the medium was replaced, and after 21 days of culture, the cells were fixed with $1 \%$ formaldehyde and tested using a VECTASTAIN ABC-AP kit (Vector Laboratories) for cross-reactivity with the monoclonal antibody 23c6 (CD51), which recognizes the OCL vitronectin receptor. The 23c6-positive multinucleated cells were scored using an inverted microscope by an observer without knowledge of the treatment group.

Polymerase chain reaction amplification of RT-PCR. GM-CFU-derived cells were cultured for 2 days and subjected to RT-PCR analysis for expression of $M V N P$ and $T A F_{I I} 17$. The gene-specific primers for human $M V N P$ were 5 '-CAGATTATGAACCAGTTTGGCCCTTCA-3' (sense) and 5'-CCTGTGTTATTTCTTGGTTGTTTTCCC-3' (antisense). The gene-specific primers for human $T A F_{I I}-17$ were 5'-CATGCCATGGCTATGAACCAGTTTGGCCCCTCA-3' (sense) and 5'-ATACTGCAGTTATTTCTTGGTTGTTTTCCG-3' (antisense). The genespecific primers for $\beta$-actin were $5^{\prime}$-GGCCGTACCACTGGCATCGTGATG-3' (sense) and 5'-CTTGGCCGTCAGGCAGCTCGTAGC-3' (antisense). Con- ditions for amplification were as follows: $94^{\circ} \mathrm{C}$ for 5 minutes, 35 cycles at $94^{\circ} \mathrm{C}$ for 1 minute, $55^{\circ} \mathrm{C}$ for 1 minute, and $72^{\circ} \mathrm{C}$ for 1 minute, followed by extension at $72^{\circ} \mathrm{C}$ for 7 minutes. PCR products were separated by $2 \%$ agarose gel electrophoresis and were visualized by ethidium bromide staining with ultraviolet light illumination (6).

Production of WT $p 62$ and $p 62^{P 392 L}$ vectors. A plasmid containing the fulllength human $p 62$ cDNA was kindly provided by J. Moscat (University of Cincinnati, Cincinnati, Ohio, USA), and the P392L mutation (a C-to-T transition) was introduced by PCR-based site-directed mutagenesis. The mutagenized cDNA was fully sequenced to verify correct introduction of the P392L mutation. Retroviral constructs containing the $p 62$ or $p 62^{\text {P392L }}$ cDNAs under the control of the $\mathrm{CMV}$ promoter were prepared and transfected into normal human OCL precursors as previously described (15). In brief, the $p 62$ or $p 62^{P 392 L} \mathrm{cDNAs}$ were inserted into the $X h o \mathrm{I}$ site of the $p-L X S N$ retroviral vector, and the recombinant plasmid constructs were transfected into the PT67 amphotropic packaging cell line using calcium phosphate. Stable cloned cell lines producing recombinant retrovirus at $10^{6}$ virus particles $/ \mathrm{ml}$ were established by selecting for resistance to neomycin $(600 \mu \mathrm{g} / \mathrm{ml})$. Similarly, a control retrovirus producer cell line was also established by transfecting the cells with the $p-L X S N E V$. Producer cell lines were maintained in DMEM containing 10\% FBS, $100 \mathrm{U} / \mathrm{ml}$ streptomycin/penicillin, $4 \mathrm{mM}$ L-glutamine, 
A
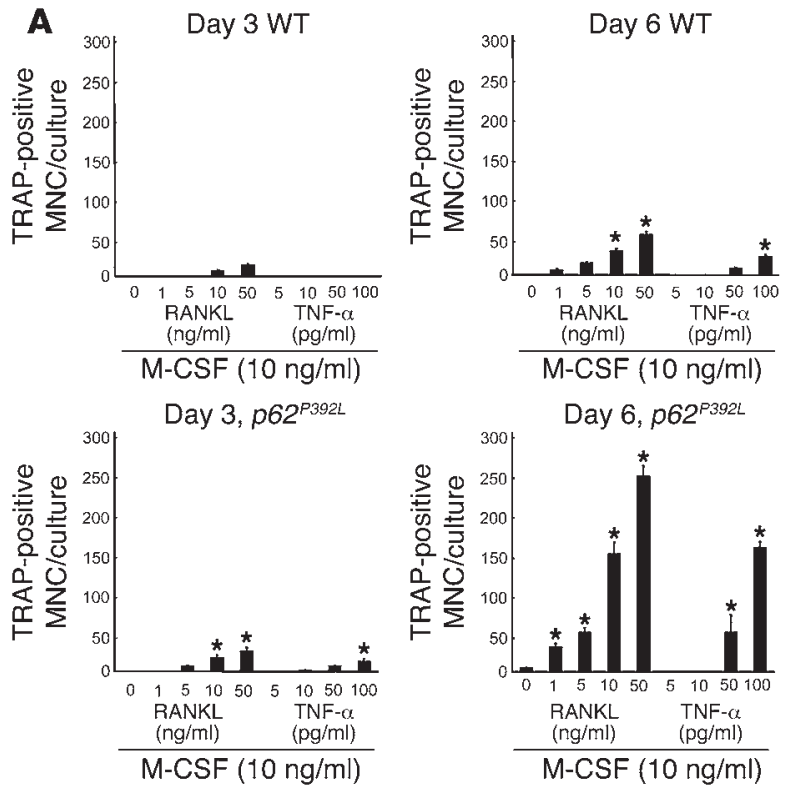

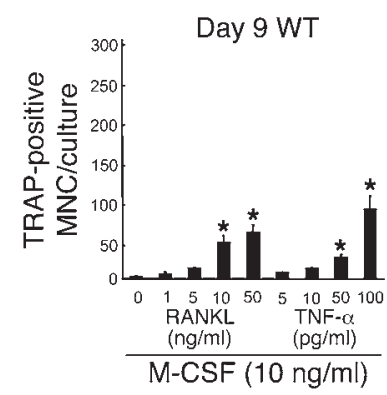

Day $9, p 62^{P 392 L}$

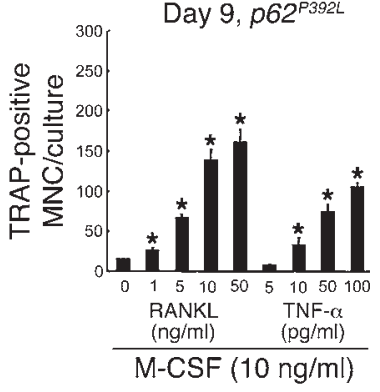

B

Day 2

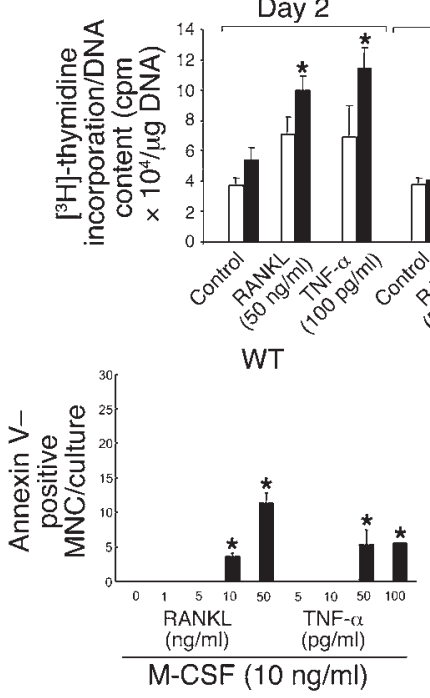

Day 4

Day 6

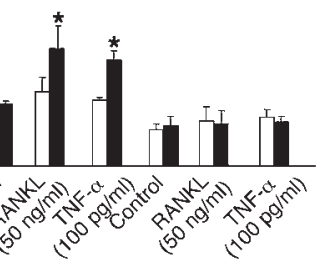

C

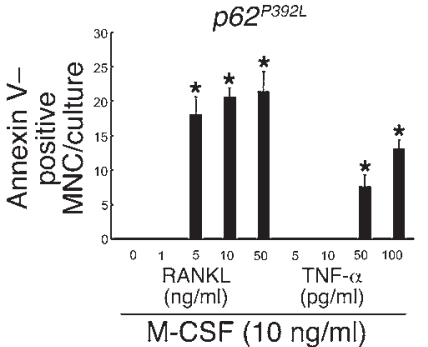

Figure 6

Time course for $\mathrm{OCL}$ formation, $\mathrm{OCL}$ precursor proliferation, and $\mathrm{OCL}$ apoptosis by marrow cells from TRAP-p62P392L or WT mice. (A) OCL precursors $\left(10^{5}\right.$

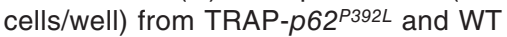
mice were cultured in the presence of RANKL or TNF- $\alpha$. After 3, 6 , or 9 days of culture, cells were fixed and number of TRAP-positive OCLs counted. (B) OCL precursors $\left(1 \times 10^{6}\right.$ per culture) from WT (white bars) and TRAP-p62 ${ }^{\text {P392L }}$ (black bars) littermate mice were cultured for 2 , 4 , or 6 days and were pulsed at the end of the culture period for 1 hour with $1 \mathrm{mCi}$ $\left[{ }^{3} \mathrm{H}\right]$-thymidine. Radioactivity was counted by liquid scintillation spectrometry. Results are expressed as the mean \pm SD for quadruplicate cultures. ${ }^{*} P<0.001$ compared with results of WT cultures treated with the same concentration of RANKL or TNF- $\alpha$. (C) OCL precursors ( $10^{5}$ cells/well) from TRAP-p62 ${ }^{\text {P392L }}$ and WT mice were cultured in the presence of RANKL or TNF- $\alpha$. After 9 days of culture, cells were fixed and number of apoptotic OCLs were counted using a commercial Annexin V kit (Promega). All results are expressed as the mean $\pm \mathrm{SD}$ for quadruplicate cultures. and high glucose $(4.5 \mathrm{~g} / \mathrm{l})$. Retroviral supernatants from the producer cell cultures were collected and filtered $(0.45 \mu \mathrm{m})$ for immediate use. The retrovirus stocks were demonstrated to be helper free by a marker assay. Viral titers present in the culture supernatants were determined by testing for multiplicity of infection with serial dilutions of the supernatants on NIH3T3 cells and scoring the number of G418-resistant CFUs formed (following exposure to $250 \mu \mathrm{g} / \mathrm{ml} \mathrm{G418)}$ as described (15).

Overexpression of $p 62$ and $p 62^{P 392 L}$ in normal buman OCL precursors. After obtaining informed consent, we obtained bone marrow aspirates from normal volunteers as previously described (15). These studies were approved by the Institutional Review Board at the University of Pittsburgh. Human bone marrow mononuclear cells were cultured for 2 days in $\alpha$-MEM containing $10 \% \mathrm{FBS}$ and $10 \mathrm{ng} / \mathrm{ml}$ each of IL-3, IL-6, and SCF. The bone marrow cells were cultured for an additional 48 hours with varying amounts of viral supernatant $(1-10 \% \mathrm{v} / \mathrm{v})$ containing the $p 62$ or $p 2^{\text {P392L }}$ vectors or $E V$. Cultures were supplemented with $4 \mu \mathrm{g} / \mathrm{ml}$ of polybrene, $20 \mathrm{ng} / \mathrm{ml}$ of IL-3, $50 \mathrm{ng} / \mathrm{ml}$ of IL-6, and $100 \mathrm{ng} / \mathrm{ml}$ of SCF. We previously determined that this was the optimum cytokine combination that supported the highest transduction efficiency. After 24 hours, cells were centrifuged, spent supernatant was removed, and freshly prepared viral supernatant supplemented with $4 \mu \mathrm{g} / \mathrm{ml}$ of polybrene and growth factors was added; then the cultures were continued for an additional 24 hours. After 48 hours, cells were harvested for short-term GM-CFU assays in methylcellulose as previously described $(15,19)$, and an aliquot of the cells was evaluated for p62 expression by immunostaining with an antip62 monoclonal antibody (BD Biosciences).

Bone resorption assays. GM-CFU-derived cells transduced with $p 62^{\text {P392L }}$ or $E V\left(10^{5}\right.$ cells/well) were cultured with RANKL (50 ng/ml) or TNF- $\alpha$ $(100 \mathrm{pg} / \mathrm{ml})$ on mammoth dentin slices (Wako). After 3 weeks of culture, cells were removed, dentin slices were stained with acid hematoxylin, and areas of dentin resorption were determined using image analysis techniques, as previously described (20).

Construction of the TRAP-p62 $2^{P 392 L}$ bybrid transgene. We have previously described construction of the $\mathrm{p}-\mathrm{BSmTRAP5}$ ' plasmid, which contains $1294 \mathrm{bp}$ of the $5^{\prime}$ flanking sequence as well as the entire $5^{\prime}$ untranslated region of the murine TRAP gene (21). The full-length human $p 62^{P 392 L} \mathrm{cDNA}$ described above was inserted into the unique EcoRI site of $p$-BSpKCR3 (21), which contains part of the second exon, the second intron, and the third exon, including the polyadenylation site of the rabbit $\beta$-globin gene. There are 


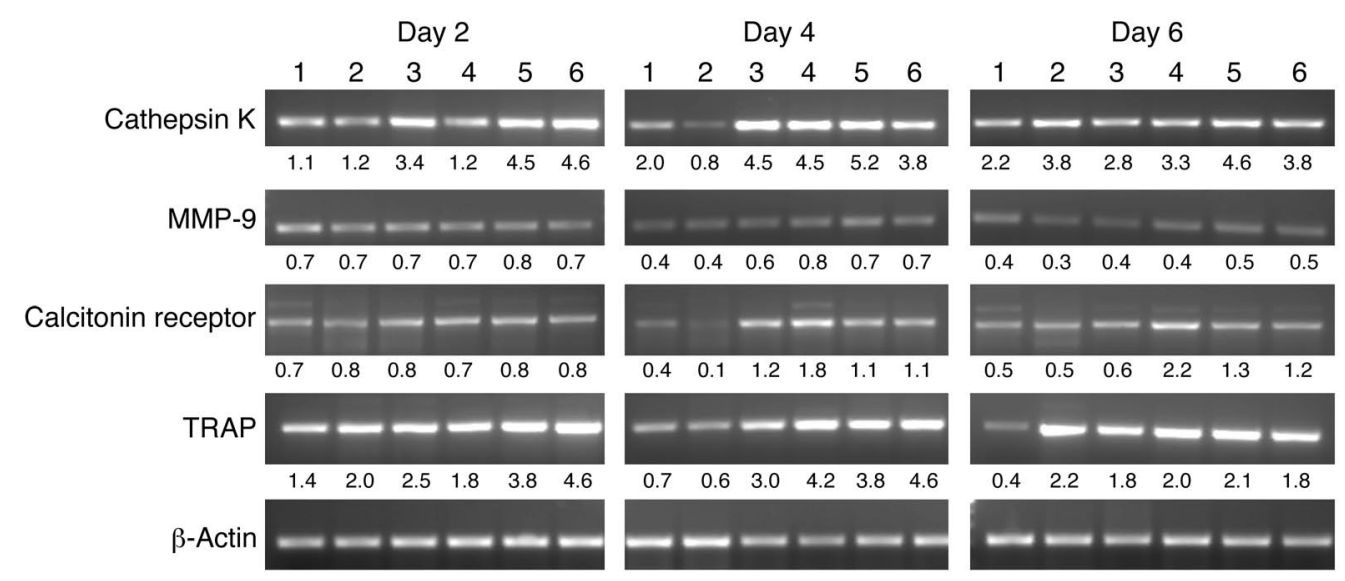

\section{Figure 7}

Expression of markers of OCL differentiation by TRAP-p62 ${ }^{P 392 L}$ and WT OCL precursors. OCL precursors (106 cells) from WT and TRAP-

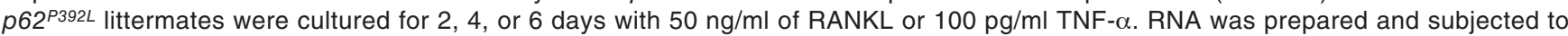
RT-PCR analysis for cathepsin K, MMP-9, calcitonin receptor, and TRAP as described in Methods. Ratio of marker mRNA expression to $\beta$-actin is shown below each lane. Lane 1 , WT M-CSF (10 ng/ml); lane 2, WT M-CSF (10 ng/ml) plus RANKL (50 ng/ml); lane 3, WT M-CSF

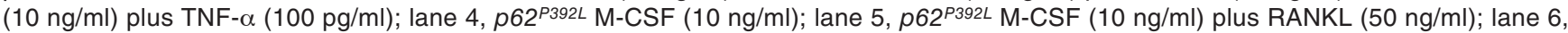
p62 ${ }^{\text {P392L }} \mathrm{M}-\mathrm{CSF}(10 \mathrm{ng} / \mathrm{ml})$ plus TNF- $\alpha(100 \mathrm{pg} / \mathrm{ml})$.

no AUG initiation codons within the $\beta$-globin sequences upstream of the cDNA insertion site, so translation of the $p 62^{P 392 L}$ protein starts at the normal $p 62$ initiation codon. The murine TRAP promoter was then inserted into the multiple cloning site immediately upstream of the rabbit $\beta$-globin sequences. The TRAP-p62 ${ }^{P 392 L}$ transgene was excised by XhoI digestion from the resulting plasmid, p-KCR3-TRAP- $p 62^{P 392 L}$, and was agarose gel purified before microinjection.

Production and identification of TRAP-p62 ${ }^{P 392 L}$ transgenic mice. These studies were approved by the Institutional Animal Care and Use Committee at Virginia Commonwealth University. The TRAP-p62 $2^{P 392 L}$ transgene was microinjected at a concentration of $3 \mu \mathrm{g} / \mathrm{ml}$ into the male pronucleus of fertilized 1-cell mouse embryos by standard methods (22). The embryos were obtained from mating $\mathrm{CB}_{6} \mathrm{~F}_{1}(\mathrm{C} 57 \mathrm{BL} / 6 \times \mathrm{BALB} / \mathrm{c})$ males and females (Harlan). The injected embryos were then reimplanted into the oviducts of pseudopregnant CD-1 female mice. The presence of the transgene was identified in resulting offspring by Southern blot analysis of genomic DNA prepared from a small tail-tip biopsy taken at the time of weaning. Probes for Southern blot analysis were generated by random oligonucleotide labeling (Amersham Biosciences) using $\left[\alpha^{-32} \mathrm{P}\right] \mathrm{dCTP}$ (DuPont/NEN). Transgenic mice of subsequent generations were identified by PCR analysis using transgene-specific primers. The upstream primer was derived from the murine TRAP5' untranslated region: 5'-GTCCTCACCAGAGACTCTGAACTC-3' (sense); and the downstream primer was derived from the human p62 cDNA: 5'-TGAGCGACGCCATAGCGAGCGG-3' (antisense). The conditions for amplification were as follows: $94^{\circ} \mathrm{C}$ for 2 minutes, 35 cycles at $94^{\circ} \mathrm{C}$ for 1 minute, $60^{\circ} \mathrm{C}$ for 1 minute, and $72^{\circ} \mathrm{C}$ for 2 minutes, followed by extension at $72^{\circ} \mathrm{C}$ for 7 minutes. PCR products were separated by $1.25 \%$ agarose gel electrophoresis and were visualized by ethidium bromide staining with ultraviolet light illumination.

Histologic analysis of TRAP-p $62^{\text {P392L }}$ vertebral bones. The first through fourth lumbar vertebrae from 4-, 8-, 12-, and 16-month-old TRAP-p62 $2^{P 392 L}$ and WT littermates were fixed in 10\% buffered formalin for 24-48 hours, then completely decalcified in $10 \%$ EDTA at $4^{\circ} \mathrm{C}$, processed through graded alcohols, and embedded in paraffin. Longitudinal sections of $5 \mu \mathrm{m}$ were cut and mounted on glass slides. Deparaffinized sections were stained for TRAP as described by Liu et al. (23). OCLs containing active
TRAP were stained red. Another set of sections was stained with $0.1 \%$ toluidine blue. Histomorphometry was performed on the region of cancellous bone between the cranial and caudal growth plates of the third lumbar vertebral body under bright field and polarized light at a magnification of $\times 200$, using the OsteoMeasure $4.00 \mathrm{C}$ morphometric program (OsteoMeasure; OsteoMetrics). OCL perimeter was defined as the length of bone surface covered with TRAP-positive and mono- and multinuclear cells. Osteoblast perimeter, cancellous bone volume, trabecular width, trabecular number, and trabecular separation were also quantified and calculated. All variables were expressed and calculated according to the recommendations of the American Society for Bone and Mineral Research Nomenclature Committee $(24,25)$.

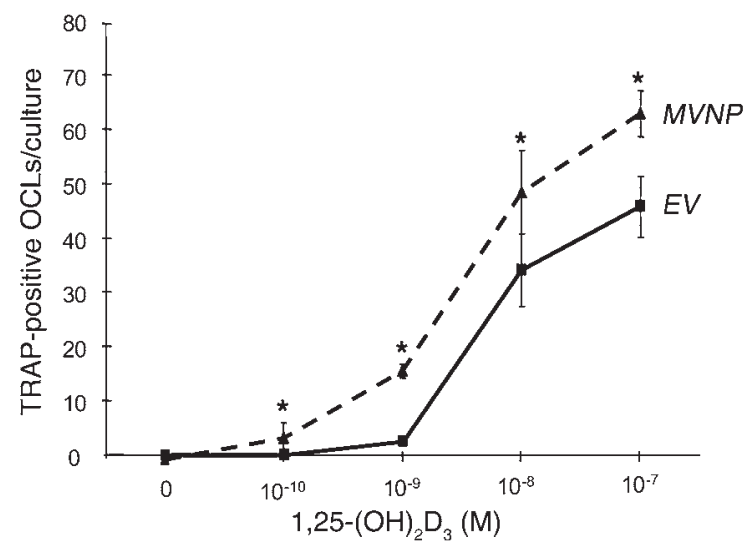

\section{Figure 8}

MVNP-transduced TRAP-p62P392L mouse GM-CFU cells are hyperresponsive to $1,25-(\mathrm{OH})_{2} \mathrm{D}_{3}$. OCL precursors $\left(5 \times 10^{5}\right.$ cells $/$ well $)$ from MVNP- or EV-transduced TRAP-p62 ${ }^{P 392 L}$ mouse GM-CFU were cultured in the presence of $1,25-(\mathrm{OH})_{2} \mathrm{D}_{3}$. After 9 days of culture, cells were fixed and stained for TRAP activity. Results are expressed as the mean \pm SEM for quadruplicate cultures. ${ }^{*} P<0.001$ compared with results of cultures of EV-transduced GM-CFU treated with the same concentration of $1,25-(\mathrm{OH})_{2} \mathrm{D}_{3}$. 
$N F-\kappa B$ gene reporter activity in $p 62^{P 392 L}$ and WT marrow cells. For reporter gene assays, GM-CFU-derived cells from TRAP-p62 $2^{\text {P392L }}$ mice or WT littermate controls were cotransfected with a luciferase reporter plasmid containing an NF- $\kappa \mathrm{B}-$ responsive promoter (Clontech; Cambrex) and a $\beta$-gal expression plasmid using the FuGENE 6 Reagent (Roche Diagnostics). Sixteen hours after transfection, varying concentrations of RANKL or TNF- $\alpha$ were added. Twenty-four hours later, cells were harvested and lysed in the cell lysate solution provided with the luciferase assay kit (Promega). The luciferase activities of the cell lysates were measured with the luciferase assay kit according to the manufacturer's instructions and were normalized to $\beta$-gal activities of the same cell lysates using a $\beta$-gal assay kit (Promega).

Measurement of OCL differentiation markers in TRAP-p62 $2^{P 392 L}$ and WT marrow cells by polymerase chain reaction amplification of RT-PCR. Marrow cells from TRAP-p $62^{P 392 L}$ or WT mice were cultured for 2, 4, or 6 days with M-CSF $(10 \mathrm{ng} / \mathrm{ml})$ alone, RANKL $(50 \mathrm{ng} / \mathrm{ml})$ and M-CSF, or TNF- $\alpha$ $(100 \mathrm{pg} / \mathrm{ml})$ and M-CSF. Total RNA was extracted using RNAzol B solution (Tel-Test Inc.) and reverse transcribed as follows: $5 \%$ of the first-strand cDNA pool was subjected to PCR amplification using gene-specific PCR primers following standard PCR protocols. The gene-specific primers for mouse cathepsin $K$ were $5^{\prime}$-GCAGAACGGAGGCATTGAC-3' (sense) and 5'TGGCTGGAATCACATCTTGG-3' (antisense). The gene-specific primers for mouse MMP-9 were 5'-TTGGTTTCTGCCCTAGTTAG-3' (sense) and 5'-TGCCCAGGAAGACGAAGG-3' (antisense). The gene-specific primers for mouse calcitonin receptor were 5'-CCCAGACATCCAGCAAGAG' (sense) and $5^{\prime}$-CAGCACATCCAGCCATCC-3' (antisense). The gene-specific primers for mouse TRAP were 5'-GAACTTCCCCAGCCCTTA-3' (sense) and 5'CCCACTCAGCACATAGCC-3' (antisense). The gene-specific primers for mouse $\beta$-actin were $5^{\prime}$-GGCCGTACCACTGGCATCGTGATG-3' (sense) and $5^{\prime}$-CCTGGCCGTCAGGCAGCTCGTAGC-3' (antisense). The conditions for amplification were as follow: $94^{\circ} \mathrm{C}$ for 5 minutes, 35 cycles at $94^{\circ} \mathrm{C}$ for 1 minute, $55^{\circ} \mathrm{C}$ for 1 minute, and $72^{\circ} \mathrm{C}$ for 1 minute, followed by extension at $72^{\circ} \mathrm{C}$ for 7 minutes. PCR products were separated by $2 \%$ agarose gel electrophoresis and were visualized by ethidium bromide staining with ultraviolet light illumination.

Transduction of OCL precursors from TRAP-p62 $2^{P 392 L}$ or WT mice with MVNP. Bone marrow cells were obtained by flushing the femurs of TRAP- $p 62^{P 392 L}$ or WT mice with $\alpha$-MEM, and cells were collected by centrifugation at $300 \mathrm{~g}$ for 10 minutes. The cells were resuspended at $2.5 \times 10^{6} \mathrm{cells} / \mathrm{ml}$ and cultured in $\alpha$-MEM containing $10 \mathrm{ng} / \mathrm{ml}$ each of IL-3, IL- 6 , and SCF for 2 days to induce proliferation of hematopoietic precursors. The marrow cells were then transduced with retroviral vectors that contained a neomycin resistance gene and the MVNP gene or $E V(15)$. The transduced cells were cultured in methylcellulose with mouse GM-CSF (200 pg/ml) in the presence of $250 \mu \mathrm{g} / \mathrm{ml} \mathrm{G} 418$ to select for GM-CFU colonies that expressed MVNP or EV. GM-CFU colonies were scored after 7 days of culture, using an inverted microscope. Colonies were individually picked, using finely drawn pipettes. GM-CFU-derived cells used for OCL formation assays are described below. We have previously demonstrated that these cells are highly purified early OCL precursors (15). GM-CFU-derived cells $\left(10^{6}\right.$ cells $\left./ \mathrm{ml}\right)$ obtained as described above (15) were plated in 96-well plates in $\alpha$-MEM containing $10 \%$ FBS and cultured in the presence of $1,25-(\mathrm{OH})_{2} \mathrm{D}_{3}$ to induce OCL formation. The cultures were fed every 3 days by replacing half the medium, and after 6 days of culture, the cells were fixed with $1 \%$ formaldehyde and stained for TRAP using a leukocyte acid phosphatase kit (Sigma-Aldrich). The TRAP-positive multinucleated cells were scored using an inverted microscope.

Immunoblotting of OCL precursors from TRAP-p $62^{P 392 L}$ or WT mice. Cytokinetreated or control OCL precursors from TRAP-p62 $2^{\text {P392L }}$ or WT mice were washed twice with ice-cold PBS. Cells were lysed in the buffer containing $20 \mathrm{mM}$ Tris, pH 7.5, $150 \mathrm{mM} \mathrm{NaCl}, 1 \mathrm{mM}$ EDTA, 1 mM EGTA, 1\% Triton $\mathrm{X}$-100, $2.5 \mathrm{mM}$ sodium pyrophosphate, $1 \mathrm{mM} \beta$-glycerophosphate, $1 \mathrm{mM}$ $\mathrm{Na}_{3} \mathrm{VO}_{4}, 1 \mathrm{mM} \mathrm{NaF}$, and $\times 1$ protease inhibitor mixture. Fifty micrograms of cell lysates were boiled in the presence of SDS sample buffer $(0.5 \mathrm{M}$ Tris$\mathrm{HCl}, \mathrm{pH} 6.8,10 \%[\mathrm{w} / \mathrm{v}]$ SDS, $10 \%$ glycerol, $0.05 \%$ [w/v] bromphenol blue) for 5 minutes and subjected to electrophoresis on 7.5\% SDS-PAGE. Proteins were transferred to nitrocellulose membranes using a semi-dry blotter (Bio-Rad) and incubated in blocking solution (5\% nonfat dry milk in TBS containing $0.1 \%$ Tween-20) for 1 hour to reduce nonspecific binding. Membranes were then exposed to primary antibodies overnight at $4{ }^{\circ} \mathrm{C}$, washed 3 times, and incubated with secondary goat anti-mouse or rabbit IgG HRP-conjugated antibody for 1 hour. Membranes were washed extensively, and enhanced chemiluminescence detection assay was performed following the manufacturer's directions (Bio-Rad). All blots were densitometrically quantitated and the results expressed relative to control and normalized to $\beta$-actin.

Statistics. Significance was evaluated using a 2-tailed, unpaired Student's $t$ test, with $P<0.05$ considered to be significant.

\section{Acknowledgments}

This work was supported by research funds from the NIH grant PO1-AR049363 and US Army Medical Research \& Materiel Command (USAMRMC) award DAMD17-03-1-0763 and is the result of work supported with resources and the use of facilities at the VA Pittsburgh Healthcare System, Research and Development. We acknowledge the General Clinical Research Center at the University of Pittsburgh for assistance with obtaining the marrow samples and the VCU Massey Cancer Center L.T. Christian III Transgenic Mouse Core Facility, which is supported by NIH grant P30-CA16059. J.J. Windle wishes to thank Heju Zhang and Christina Boykin for assistance with transgenic mouse production. H.E. Gruber wishes to thank Daisy Ridings for expert assistance with electron microscopy.

Received for publication February 17, 2006, and accepted in revised form November 13, 2006.

Address correspondence to: Noriyoshi Kurihara, VA Pittsburgh Healthcare System, Research and Development (151C-U), University Drive C, Pittsburgh, Pennsylvania 15240, USA. Phone: (412) 688-6000 ext. 81-4990; Fax: (412) 688-6960; E-mail: kuriharan@upmc.edu.
1. Tiegs, R.D., Lohse, C.M., Wollan, P.C., and Melton, L.J. 2000. Long-term trends in the incidence of Paget's disease of bone. Bone. 27:423-427.

2. Siris, E.S. 1998. Paget's disease of bone. J. Bone Miner. Res. 13:1061-1065.

3. Kukita, A., Chenu, C., McManus, L.M., Mundy, G.R., and Roodman, G.D. 1990. Atypical multinucleated cells form in long-term marrow cultures from patients with Paget's disease. J. Clin. Invest. 85:1280-1286.

4. Menaa, C., et al. 2000. 1,25-Dihydroxyvitamin $\mathrm{D}_{3}$ hypersensitivity of osteoclast precursors from patients with Paget's disease. J. Bone Miner. Res. 15:228-236.

5. Neale, S.D., Smith, R., Wass, J.A., and Athanasou, N.A. 2000. Osteoclast differentiation from circulating mononuclear precursors in Paget's disease is hypersensitive to 1,25-dihydroxyvitamin $\mathrm{D}_{3}$ and RANKL. Bone. 27:409-416.

6. Kurihara, N., et al. 2004. Role of TAFII-17, a VDR binding protein, in the increased osteoclast formation in Paget's disease. J. Bone Miner. Res. 19:1154-1164.

7. Laurin, N., Brown, J.P., Morissette, J., and Raymond, V.
2002. Recurrent mutation of the gene encoding sequestosome 1 (SQSTM1/p62) in Paget disease of bone. Am. J. Hum. Genet. 70:1582-1588.

8. Hocking, L.J., et al. 2002. Domain-specific mutations in sequestosome 1 (SQSTM1) cause familial and sporadic Paget's disease. Hum. Mol. Genet. 11:2735-2739.

9. Sanz, L., Sanchez, P., Lallena, M.J., Diaz-Meco, M.T., and Moscat, J. 1999. The interaction of $\mathrm{p} 62$ with RIP links the atypical PKCs to NF-kappaB activation. EMBO J. 18:3044-3053.

10. Sanz, L., Diaz-Meco, M.T., Nakano, H., and Moscat, J. 
2000. The atypical PKC-interacting protein $\mathrm{p} 62$ channels NF-kappaB activation by the IL-1-TRAF6 pathway. EMBO J. 19:1576-1586.

11. Johnson-Pais, T.L., et al. 2003. Three novel mutations in SQSTM1 identified in familial Paget's disease of bone. J. Bone Miner. Res. 18:1748-1753.

12. Falchetti, A., et al. 2005. Segregation of a M404V mutation of the p62/sequestosome 1 (p62) SQSTM1) gene with polyostotic Paget's disease of bone in an Italian family. Arthritis Res. Ther. 7:R1289-R1295

13. Singer, F.R., Lin, G., Hoon, D.S.B., Johnson-Pais, T.L., and Leach, R.J. 2004. Absence of evidence of Paget's disease of bone in subjects who harbor sequestosome 1 mutations [abstract]. J. Bone Miner. Res. 19:M520.

14. Kurihara, N., et al. 2006. Expression of the measles virus nucleocapsid protein in osteoclasts in vivo induces Paget's disease-like bone lesions in mice. J. Bone Miner. Res. 21:446-455.

15. Kurihara, N., Reddy, S.V., Menaa, C., Anderson, D., and Roodman, G.D. 2000. Osteoclasts expressing the measles virus nucleocapsid gene display a pagetic phenotype. J. Clin. Invest. 105:607-614.
16. Cavey, J.R., et al. 2005. Loss of ubiquitin-binding associated with Paget's disease of bone p62 (SQSTM1) mutations. J. Bone Miner. Res. 20:619-624.

17. Duran, A., et al. 2004. The atypical PCK-interacting protein $\mathrm{p} 62$ is an important mediator of RANK-activated osteoclastogenesis. Dev. Cell. 6:303-309.

18. Kurihara, N., Chenu, C., Miller, M., Civin, C., and Roodman, G.D. 1990. Identification of committed mononuclear precursors for osteoclast-like cells formed in long term human marrow cultures. Endocrinology. 126:2733-2741.

19. Kurihara, N., Civin, C., and Roodman, G.D. 1991. Osteotropic factor responsiveness of highly purified populations of early and late precursors for human multinucleated cells expressing the osteoclast phenotype. J. Bone Miner. Res. 6:257-261.

20. Ishizuka, S., et al. 2005. (23S)-25-Dehydro-1\{alpha\}hydroxyvitamin D3-26,23-lactone, a vitamin D receptor antagonist that inhibits osteoclast formation and bone resorption in bone marrow cultures from patients with Paget's disease. Endocrinology. 146:2023-2030.

21. Reddy, S.V., et al. 1995. Characterization of the mouse tartrate-resistant acid phosphatase (TRAP) gene promoter. J. Bone Miner. Res. 10:601-606.

22 Nagy, A., Gertsenstein, M., Vintersten, K., and Behringer, R. 2002. Manipulating the mouse embryo: a laboratory manual. 3rd edition. Cold Spring Harbor Laboratory Press. Cold Spring Harbor, New York, USA. 800 pp.

23. Liu, B., Yu, S.F., and Li, T.J. 2003. Multinucleated giant cells in various forms of giant cell containing lesions of the jaws express features of osteoclasts. J. Oral Pathol. Med. 32:367-375.

24. American Society for Bone and Mineral Research President's Committee on Nomenclature. 2000. Proposed standard nomenclature for new tumor necrosis factor family members involved in the regulation of bone resorption. The American Society for Bone and Mineral Research President's Committee on Nomenclature. J. Bone Miner. Res. 15:2293-2296.

25. Parfitt, A.M., et al. 1987. Bone histomorphometry: standardization of nomenclature symbols, and units. Report of the ASBMR Histomorphometry Nomenclature Committee. J. Bone Miner. Res. 2:595-610. 